\title{
Mathematical Modeling of Information Warfare in a Society
}

\author{
Mikhailov A. P. \\ Prof., Doctor of Physics and Mathematics, Head of Sector at Keldysh Institute of Applied Mathematics Russian Academy of \\ Sciences, Head of Laboratory of Faculty of Sociology at Lomonosov Moscow State University. Research interests: \\ Mathematical Modeling of Social Processes, the Author of more than 280 Works; apmikhailov@yandex.ru
}

\begin{abstract}
Petrov A. P.
Doctor of Physics and Mathematics, Leading researcher at Keldysh Institute of Applied Mathematics Russian Academy of Sciences Research interests: mathematical modeling of social processes, the author of about 100 works; petrov.alexander.p@yandex.ru
\end{abstract}

Proncheva 0. G.

Postgraduate at Keldysh Institute of Applied Mathematics Russian Academy of Sciences. Research interests: Mathematical Modeling of social Processes, the Author of 15 Works; olga.proncheva@gmail.com

Marevtseva N. A.

Candidate of Physics and Mathematics, Senior scientist at Faculty of Sociology of Lomonosov Moscow State University Research Interests: Mathematical Modeling of Social Processes, the Author of 18 Works; marevna@mail.ru

\section{Doi:10.5901/mjss.2015.v6n5s2p27}

\begin{abstract}
Mathematical models of information attack and information warfare in a society are considered. The models take into account the information dissemination through interpersonal communications and medi propaganda, as well as the heterogeneity of a society. The process of confrontation is represented as follows. There are two opposing information sources in a society, so each individual can become an spreader of information of either one or the other information source, depending on whose information she receives first. The models also take into account the following factors of information dissemination: incomplete media coverage, two-step perception of information, forgetting of information by individuals. The model has the form of the Cauchy problem for nonlinear system of ordinary differential equations. This model is studied analytically and numerically. The meaningful interpretation is given for the results obtained.
\end{abstract}

Keywords: mathematical modeling, interpersonal communication, media propaganda.

\section{Introduction}

The current stage of social development is characterized by a sharply increasing role of information environment. Therefore national security stronger and stronger depends on its information aspect. Modern approaches to the humanitarian problems of information security (i.e. the problems associated with the "human factor") can be significantly enriched with mathematical methods. These include, above all, the use of appropriate mathematical models (Samarskii, Mikhailov, 2000, 2001, 2004).

In this paper we create and investigate mathematical models that describe the processes of information attacks and information warfare.

The models are constructed under reasonable and interpretable assumptions. Within the limits of their applicability they allow to examine qualitatively the nature of these processes. We can formulate and solve problems (see Mikhailov, Izmodenova, 2004, 2005) of finding the optimal, in some specific sense, method of their organization. It is shown that the studied processes of information attacks and information warfare, because of their non-linearity, allow no obvious development regime. Thus, substantial characteristics, control of which can stimulate the flow of these processes in the necessary for their members direction, are determined even in the simplest cases of the analysis of mathematical models of information attacks and information warfare.

The rest of the paper is structured as follows: section 2 presents the basic model of information attack, section 3 
presents the basic model of information warfare, section 4 contains some additional factors, section 5 presents the model of information warfare with three additional factors and section 6 concludes the paper.

\section{Basic Model of Information Attack}

Before we start with the description of the basic model, consider the paper (Yanagizanava-Drott, 2014) about the Rwandan genocide and the role of mass-media in it. It was obtained, that there were direct effects of mass-media (local radio station $\mathrm{RTLM}$ ), as well as indirect. Direct effect is that people get information while listening radio station, and extremist messages induce violence against Tutsi minority. Indirect effect is that people who don't listen the radio get information through communication with their neighbors, who have access to the radio, and more than that, the effect is bigger for individuals, who listen radio because of communication. For certain groups the second effect was even bigger. So, there are two channels of information dissemination: mass-media and interpersonal communications.

In this paper we take the model of information attack (see Samarskii, Mikhailov 2001; Mikhailov, Klusov, 2002) as the basic model. Consider the process of information dissemination in a group of interacting individuals. Let the size of this group be $N_{0}$. The model assumes that an individual who is ignorant of the information can get it either through the media or interpersonal communication with previously informed individual (spreader). The number of spreaders at time $t$ is denoted by $X(t)$. Positive parameters $\alpha$ and $\beta$ describe the intensity of the information dissemination by these means respectively, with these parameters are taken to be time-independent. Note that the intensity of information dissemination through interpersonal communication is also proportional to the number of spreaders. It is assumed that the rate of information dissemination (i. e. the number of individuals covered per unit of time), is composed of the rates of information dissemination of both channels. This rate is proportional to the number of ignorants, i.e. No $-X(t)$.

The basic model of informational attack has the following form:

$\frac{\mathrm{dX}}{\mathrm{dt}}=(\alpha+\beta \mathrm{X})\left(\mathrm{N}_{0}-\mathrm{X}\right), \mathrm{X}(0)=0$

Here $N(t)$ is the number of spreaders at time $t$. The solution of (1) is

$X=N_{0} \frac{\alpha \exp \left[\left(\alpha+\beta N_{0} t\right)\right]-\alpha}{\alpha \exp \left[\left(\alpha+\beta N_{0} t\right)\right]+\beta N_{0}}$

Further this version of the model will be referred to as basic. It should be noted that there also may be other settings of this problem (non-persistent effects of information sources, time-dependent characteristic, etc.), and that the universality of mathematical models allows us to apply this model to studying other processes.

One of the main issues addressed by the models of information dissemination is the conditions under which the rate of growth of number of spreaders is maximal. This phenomenon is referred to as the maximum agiotage. equals to

It was shown by (Mikhailov, Marevtseva, 2011) that the maximum value is achieved when the number of spreaders

$X_{g}=\frac{1}{2}\left(N_{0}-\frac{\alpha}{\beta}\right)$

If $N_{0} \leq \alpha / \beta$, then the rate of growth of number of spreaders is maximal at initial moment $t=0$ and decreases over time.

The more general model

$\frac{d X}{d t}=\left(\alpha+\beta X^{\mu}\right)\left(N_{0}-X\right), X(0)=0$

were considered in (Marevtseva, Valiullin, 2014). To identify the presence of agiotage, the second derivative was calculated:

$\frac{d^{2} X}{d t^{2}}=-\beta \mu \frac{d X}{d t}\left[X^{\mu-1}\left(\frac{\mu+1}{\mu} X-N_{0}\right)+\frac{\alpha}{\beta \mu}\right]$

Obviously, if $\mu<0$ we have $d^{2} X / d t^{2}<0$, i.e. the growth of rate of the number of spreaders decreases over time.

Some other approaches to modeling the dissemination of information in a society were proposed in (Daley and Kendall, 1964; Shvedovskii 1981; Thompson et al, 2003; Gubanov et al., 2010; Petrov et al., 2015).

\section{Basic Model of Information Warfare}

Now suppose that there is a social community which is potentially exposed to not one but two competitive information sources (in particular, it may be information type $1\left(I_{1}\right)$ and type $2\left(I_{2}\right)$ diametrically opposed to each other). Let the number of this community be $N$. Suppose that at time $t=0$, two sources of different information simultaneously start broadcasting, and two information streams are distributed among the community.

Since $I_{1}$ and $I_{2}$ are not identical, the process is considered as informational warfare. The model describes the dynamics of its evolution and determines its eventual result: which of the sources is a "winner" and which is a "loser". The 
winner is the one who at the time of the full coverage of the community managed to extend its information among more members of the community than the opponent, i.e. more than $\mathrm{N}_{0} / 2$ individuals are spreaders of its information.

This model assumes that having received the information from one source, an individual is blocked for the other, that is "overpersuasion" is impossible. This assumption can be confirm empirically. It was shown by (Duffly, Rowden, 2005) that people who follow certain political views prefer to read newspapers with the same political views. So, the absence of overpersuasion can be justified.

Also, it is assumed that each source is characterized by its own values of parameters describing the intensity of the information dissemination (let it be $\alpha_{1}$ and $\alpha_{2}$ for the information dissemination through the media and $\beta_{1}$ and $\beta_{2}$ for dissemination through interpersonal communication for the first and the second source respectively). In this model the dissemination rate through interpersonal communication for each of the sources is proportional to the number of individuals covered by the same source and the number of ignorants, that is $N_{0}-X(t)-Y(t)$, where $X(t)$ is the number of spreaders of the first source and $Y(t)$ is the number of spreaders of the second source. Thus, the basic model of information warfare (see Mikhailov, Marevtseva, 2011) is as follows:

$$
\begin{aligned}
& \frac{d X}{d t}=\left(\alpha_{1}+\beta_{1} X\right)\left(N_{0}-X-Y\right), \quad X(0)=0, \\
& \frac{d Y}{d t}=\left(\alpha_{2}+\beta_{2} Y\right)\left(N_{0}-X-Y\right), \quad Y(0)=0
\end{aligned}
$$

The question about "winners" and "losers", i.e. about which information source was able to expend its information to more individuals than the opponent, is very important from practical point of view.

The necessary and sufficient condition of the victory $I_{1}$ over $I_{2}$ (i.e. the fulfillment of the inequality $X^{f}>N_{0} / 2>Y^{f}$, where $X^{f}, Y^{f}$ are the values of $X(t)$ and $Y(t)$ in the end of the process, when $X^{f}+Y^{f}=N_{0}$ ) has been obtained in (Mikhailov, Marevtseva, 2011) on the base of the analysis of the stationary solutions of the system (2). It has the form

$$
\frac{\beta_{1}}{\ln \left(1+\frac{\beta_{1} N_{0}}{2 \alpha_{1}}\right)}>\frac{\beta_{2}}{\ln \left(1+\frac{\beta_{2} N_{0}}{2 \alpha_{2}}\right)} \text {. }
$$

Accordingly, the inequality of opposite sign means "victory" $I_{2}$ ("defeat" $I_{1}$ ), and equality means "a draw". Note that for non-zero initial number of spreaders of $I_{1}$ and $I_{2}$ the condition of the victory $I_{1}$ over $I_{2}$ is also determined by the values of $X(0), Y(0)$.

In the same article model (2) was generalized to a situation of confrontation $M>2$ information sources. In that case it was a system of $\mathrm{M}$ nonlinear ordinary differential equations:

$$
\frac{d N_{i}}{d t}=\left(\alpha_{i}+\beta_{i} N_{i}\right)\left(N_{0}-\sum_{i=1}^{M} N_{i}\right), N_{i}(0)=0, i=1, . ., M
$$

\section{Account of Additional Factors}

The model that takes into account more complex factors affecting the information dissemination in a society has been proposed in (Mikhailov et al., 2014) on the basis of the above basic models. These factors are: forgetting information by individuals, non-coverage of a society by the media and the two-step adoption and forgetting of the information.

\subsection{Adoption of the information with forgetting}

Let us extend the model by including in it forgetting of the information by individuals, in other words, the possibility of transfer of the spreaders in the group of ignorants. Then the model of information attack takes the form (Mikhailov et al., 2014):

$$
\frac{d X}{d t}=(\alpha+\beta X)\left(N_{0}-X\right)-\gamma X
$$

$X(0)=X_{0}$

Here, the parameter $\gamma>0$ characterizes the intensity of information forgetting. Steady state can be found from $(\alpha+\beta X)\left(N_{0}-X\right)-\gamma X=0$

Equation (7) for any positive values $\alpha, \beta, \gamma$ and $N_{0}$ has two roots, only one of which is positive. Thus, the steadystate solution always exists and is equal to

$X^{S}=\frac{-\gamma-\alpha+\beta N_{0}+\sqrt{(\gamma+\alpha-\beta) N_{0}{ }^{2}+4 \alpha \beta N_{0}}}{2 \beta}$

Analyzing the signs of the derivatives around a stationary solution, we find that this solution is stable. 
In order to investigate the dependence of the steady-state solution on the parameters, construct the graph of the function $X^{s}(\gamma)$. For any positive values of parameters the function is convex with $X^{s}(0)=N_{0}, \lim _{\gamma \rightarrow \infty} X^{s}(\gamma)=0$. The plot of the function $X^{s}(\gamma)$ has the form shown in Figure 1. It is easy to see that for a wide range of parameter $\gamma$ dependence is almost linear.

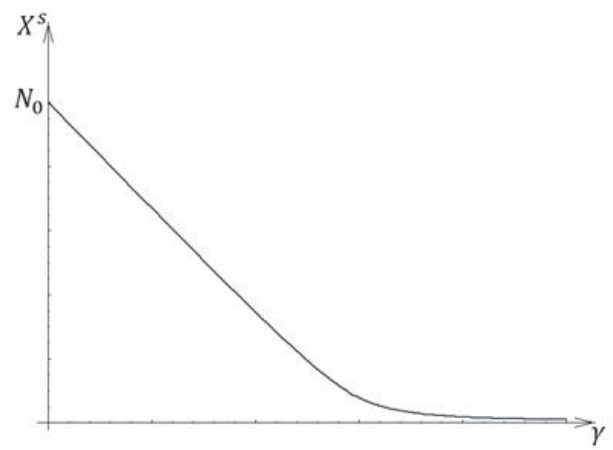

\section{Figure 1. Dependency graph $X^{\mathrm{s}}(\gamma)$}

Consider now model (5), (6) in the following aspect. Assume that the source of information can affect only the intensity of the information dissemination through the media, through the parameter $\alpha$, and other parameters are considered to be known by the source. Let the objective of this source be information covering the share $\mu$ of the total population. It means that it should state $\alpha$ for which $X^{s}=\mu N_{0}$. Solving this equation, we obtain:

$$
\alpha^{*}=\frac{\mu\left(\gamma-\beta N_{0}(1-\mu)\right)}{1-\mu}
$$

We proceed from the analysis of the steady-state solution to the study of function $X(t)$. Depending on the initial conditions, the graph of the function is of the form "1" or "2" or "3" (Fig. 2).

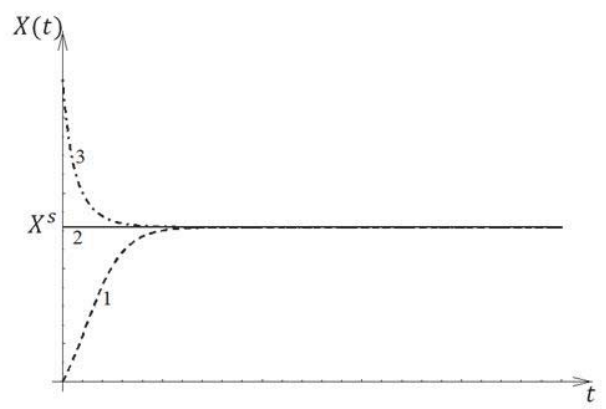

Figure 2. Graphs of the numbers of spreaders $X(t)$ under different initial conditions

If $X(0)<X^{s}$, then the function $X(t)$ is convex, and the graph looks like curve 1 ; if $X(0)=X^{s}$, then both derivatives vanish and the plot looks like curve 2; if $X(0)>X^{s}$, then the function is concave and the second one is positive and the graph looks like curve 3.

Consider now the case of zero initial conditions, i.e. $X(0)=0$. In this case, the analysis of the second derivative of the function shows that the rate of persuasion

- decreases over time, if $N_{0}<\frac{\alpha+\gamma}{\beta}$;

- $\quad$ reaches its maximum at the initial moment, and then decreases, if $N_{0}=\frac{\alpha+\gamma}{\beta}$;

- increases at the beginning and then achieve its maximum at the point of maximum agiotage, if $N_{0}>\frac{\alpha+\gamma}{\beta}$. 
Equation (5) can be solved analytically, however, due to the complexity of the solution which makes the interpretation difficult, we restrict ourselves to the important from the practical point of view case of strong propaganda. In term of the model it means that $\alpha$ is much greater than $N_{0} \beta$. Under this assumption, it is possible to use methods of the theory of singular perturbations. In accordance with the method of boundary functions (see A. Vasilieva, V. Butuzov, L. Kalachev, 1995), we represent the unknown function $X(t)$ as the sum of the boundary and regular series for the small parameter $\varepsilon=1 / \alpha$ :

$$
X(t)=\bar{X}^{0}(t)+\Pi_{0} X(\tau)+\varepsilon\left(\bar{X}^{1}(t)+\Pi_{1} X(\tau)\right)+o(\varepsilon)
$$

Here $\tau=t / \varepsilon, \Pi_{0} X(\tau), \Pi_{1} X(\tau)$ are the boundary functions such that $\lim _{\tau \rightarrow+\infty} \Pi_{i} X(\tau)=0, i=0,1$.

Substituting (10) into equation (5) and initial condition (6) and equating the coefficients of the corresponding powers of $\varepsilon$, we obtain the equations for zero and first approximation of the function. Solving them and substituting the solution in the expression (10), we obtain the first approximation of the function $X(t)$ :

$$
X(t)=1-e^{-\tau}+\varepsilon\left[\beta N_{0}-\gamma+e^{-2 \tau}\left(\beta N_{0}-2 \beta e^{\tau} N_{0}+\beta e^{\tau} N_{0} \tau+\gamma e^{\tau}-\gamma \tau e^{\tau}\right)\right]
$$

\subsection{Information dissemination in the society consisted of two groups}

So far we considered the model with only one information source. Now we extend the model with including an assumption about the society division into two groups, each of which is characterized by its own values of parameters $\beta$. Let the size of the first group be $N_{1}$, the second one be $N_{2}$. For these settings we have the following system of equations:

$$
\begin{aligned}
& \frac{d X_{1}}{d t}=\left(\alpha_{1}+\beta_{1}\left(X_{1}+X_{2}\right)\right)\left(N_{1}-X_{1}\right) \\
& \frac{d X_{2}}{d t}=\left(\alpha_{2}+\beta_{2}\left(X_{1}+X_{2}\right)\right)\left(N_{2}-X_{2}\right)
\end{aligned}
$$

Phase diagram of system (12) - (13) is shown in Fig.3 . In general case the system has three equilibrium states, but only one of them $\left(N_{1}, N_{2}\right)$ is in the first quadrant. Having linearized the system around the point of equilibrium, it is easy to find, that the type of equilibrium is a stable node. has the form:

Linearized system (12) - (13) around the equilibrium state $\left(N_{1}, N_{2}\right)$ after the substitution $\xi=X_{1}-N_{1}, \eta=X_{2}-N_{2}$

$$
\begin{aligned}
& \frac{d \xi}{d t}=\left(\alpha_{1}+\beta_{1}\left(N_{1}+N_{2}\right)\right)(-\xi) \\
& \frac{d \eta}{d t}=\left(\alpha_{2}+\beta_{2}\left(N_{1}+N_{2}\right)\right)(-\eta)
\end{aligned}
$$

Eigenvalues of matrix

$$
\left(\begin{array}{cc}
-\left(\alpha_{1}+\beta_{1}\left(N_{1}+N_{2}\right)\right) & 0 \\
0 & -\left(\alpha_{2}+\beta_{2}\left(N_{1}+N_{2}\right)\right)
\end{array}\right)
$$

are $-\left(\alpha_{1}+\beta_{1}\left(N_{1}+N_{2}\right)\right)$ and $-\left(\alpha_{2}+\beta_{2}\left(N_{1}+N_{2}\right)\right)$. Both values are negative, so the equilibrium state is a stable node.

\section{Phase portrait is shown in Fig.3}

The type of phase diagram depends on the relationship between $-\alpha_{1}-\beta_{1}\left(N_{1}+N_{2}\right)$ and $-\alpha_{2}-\beta_{2}\left(N_{1}+N_{2}\right)$. If $\left|-\alpha_{1}-\beta_{1}\left(N_{1}+N_{2}\right)\right|>\left|-\alpha_{2}-\beta_{2}\left(N_{1}+N_{2}\right)\right|$, then the phase portrait has the form shown in Fig. 3a; if $\mid-\alpha_{1}-$ $\beta_{1}\left(N_{1}+N_{2}\right)|<|-\alpha_{2}-\beta_{2}\left(N_{1}+N_{2}\right) \mid$, then the phase portrait of a form shown in Fig. $3 \mathrm{~b}$. 


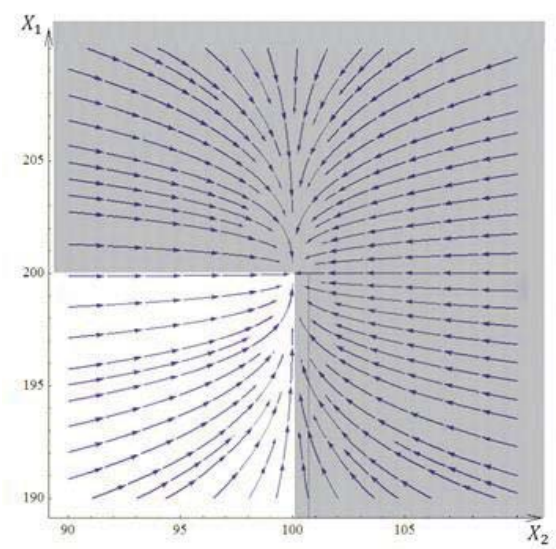

a

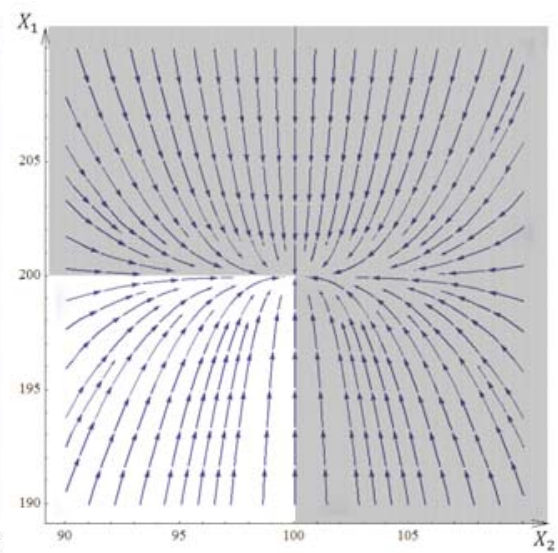

b

Figure 3. Phase portrait of the system (12)-(13). Variables domain is marked with white color. The values of parameters in fig. a: $\mathrm{N}_{1}=100 ; \mathrm{N}_{2}=200 ; \alpha_{1}=0,1 ; \alpha_{2}=0,5 ; \beta_{1}=0,9 ; \beta_{2}=0,3$. The values of parameters in fig. $\mathrm{b}: \mathrm{N}_{1}=100$; $\mathrm{N}_{2}=200 ; \alpha_{1}=0,5 ; \alpha_{2}=0,1 ; \beta_{1}=0,3 ; \beta_{2}=0,9$.

Consider now the case of two groups differ in the following way. The individual from particular group trusts more individuals of her group than individuals from another group. Then the model is described by the following system of equations:

$$
\begin{aligned}
& \frac{d X_{1}}{d t}=\left(\alpha_{1}+\beta_{1} X_{1}+\beta_{2} X_{2}\right)\left(N_{1}-X_{1}\right) \\
& \frac{d X_{2}}{d t}=\left(\alpha_{2}+\beta_{2} X_{1}+\beta_{1} X_{2}\right)\left(N_{2}-X_{2}\right) \\
& \beta_{1}>\beta_{2}
\end{aligned}
$$

System (16) - (17) also has three equilibrium states, only one of which $\left(N_{1}, N_{2}\right)$ is in the first quadrant. has the form:

Linearized system (16) - (17) around the equilibrium point $\left(N_{1}, N_{2}\right)$ after the substitution $=X_{1}-N_{1}, \eta=X_{2}-N_{2}$

$$
\begin{aligned}
& \frac{d \xi}{d t}=\left(\alpha_{1}+\beta_{1} N_{1}+\beta_{2} N_{2}\right)(-\xi) \\
& \frac{d \eta}{d t}=\left(\alpha_{2}+\beta_{2} N_{1}+\beta_{1} N_{2}\right)(-\eta)
\end{aligned}
$$

Eigenvalues of matrix

$$
\left(\begin{array}{cc}
-\left(\alpha_{1}+\beta_{1} N_{1}+\beta_{2} N_{2}\right) & 0 \\
0 & -\left(\alpha_{2}+\beta_{2} N_{1}+\beta_{1} N_{2}\right)
\end{array}\right)
$$

are $-\left(\alpha_{1}+\beta_{1} N_{1}+\beta_{2} N_{2}\right)$ and $-\left(\alpha_{2}+\beta_{2} N_{1}+\beta_{1} N_{2}\right)$. Both values are negative, so the equilibrium state is a stable node.

The type of phase portrait depends on the relationship between $-\alpha_{1}-\beta_{1} N_{1}-\beta_{2} N_{2}$ and $-\alpha_{2}-\beta_{2} N_{1}-\beta_{1} N_{2}$. If $\left|-\left(\alpha_{1}+\beta_{1} N_{1}+\beta_{2} N_{2}\right)\right|>\left|-\left(\alpha_{2}+\beta_{2} N_{1}+\beta_{1} N_{2}\right)\right|$, then the phase portrait has the form shown in Fig. 3a; if $\mid-\left(\alpha_{1}+\right.$ $\left.\beta_{1} N_{1}+\beta_{2} N_{2}\right)|<|-\left(\alpha_{2}+\beta_{2} N_{1}+\beta_{1} N_{2}\right) \mid$, then the phase portrait of a form shown in Fig. 3b.

\subsection{Two-steps information perception}

The usual assumption of models of persuasion is that effective influence requires several steps (for example, McGuire,1985). Here we assume ignorant individual becomes a spreader in two steps. After covering in the first time she becomes a pre-spreader. In particular, it means that she still does not spread information further. Pre-spreader receives and adopts the information with the same mechanisms as an uncovered individual.

Let $x(t)$ be the number of pre-spreaders. They turn into spreaders, so

$$
\frac{d X}{d t}=x(\alpha+\beta X)
$$

Since ignorants, whose number at time $t$ is $N_{0}-X(t)-x(t)$, turn into pre-spreaders, the equation for population dynamics of pre-spreaders is: 


$$
\frac{d x}{d t}=\left(N_{0}-X-2 x\right)(\alpha+\beta X)
$$

\section{The Model of Information Warfare with Three Additional Factors}

Three additional factors of information dissemination were introduced in the previous section. These factors are: incomplete coverage of society by the media, two-steps of information adoption and forgetting of the information by individuals. Now we formulate the model of information warfare, which takes into account all of these factors together. It has the following form

$$
\begin{aligned}
& \frac{d X_{1}}{d t}=x_{1}\left(\alpha_{1}+\beta_{1}\left(X_{1}+X_{2}\right)\right)-\gamma_{1} X_{1} \\
& \frac{d X_{2}}{d t}=\beta_{1} x_{2}\left(X_{1}+X_{2}\right)-\gamma_{1} X_{2} \\
& \frac{d Y_{1}}{d t}=y_{1}\left(\alpha_{2}+\beta_{2}\left(Y_{1}+Y_{2}\right)\right)-\gamma_{2} Y_{1} \\
& \frac{d Y_{2}}{d t}=\beta_{2} y_{2}\left(Y_{1}+Y_{2}\right)-\gamma_{2} Y_{2} \\
& \frac{d x_{1}}{d t}=\left(\alpha_{1}+\beta_{1}\left(X_{1}+X_{2}\right)\right)\left(N_{1}-X_{1}-Y_{1}-2 x_{1}-y_{1}\right)+\gamma_{1} X_{1}-\delta_{1} x_{1} \\
& \frac{d x_{2}}{d t}=\beta_{1}\left(X_{1}+X_{2}\right)\left(N_{2}-X_{2}-Y_{2}-2 x_{2}-y_{2}\right)+\gamma_{1} X_{2}-\delta_{1} x_{2} \\
& \frac{d y_{1}}{d t}=\left(\alpha_{2}+\beta_{2}\left(Y_{1}+Y_{2}\right)\right)\left(N_{1}-X_{1}-Y_{1}-x_{1}-2 y_{1}\right)+\gamma_{2} Y_{1}-\delta_{2} y_{1} \\
& \frac{d y_{2}}{d t}=\beta_{2}\left(Y_{1}+Y_{2}\right)\left(N_{2}-X_{2}-Y_{2}-x_{2}-2 y_{2}\right)+\gamma_{2} Y_{2}-\delta_{2} y_{2} \\
& X_{1}(0)=X_{2}(0)=Y_{1}(0)=Y_{2}(0)=x_{1}(0)=x_{2}(0)=y_{1}(0)=y_{2}(0)=0 \\
& H
\end{aligned}
$$

Here

$x_{1}-$ the number of pre-spreaders from the first group, covered by source 1 ;

$x_{2}-$ the number of pre-spreaders from the second group, covered by source 1;

$y_{1}-$ the number of pre-spreaders from the first group, covered by source 2 ;

$y_{2}-$ the number of pre-spreaders from the second group, covered by source 2 ;

$X_{1}$ - the number of spreaders from the first group, covered by source 1 ;

$X_{2}-$ the number of spreaders from the second group, covered by source 1 ;

$Y_{1}$ - the number of spreaders from the first group, covered by source 2;

$Y_{2}$ - the number of spreaders from the second group, covered by source 2;

$a_{1}$ - parameter characterizing the intensity of information dissemination through the media of the source 1 ;

$\alpha_{2}$ - parameter characterizing the intensity of information dissemination through the media of the source 2;

$\beta_{1}$ - parameter characterizing the intensity of information dissemination through the interpersonal communication of the source 1;

$\beta_{2}$ - parameter characterizing the intensity of information dissemination through the interpersonal communication of the source 2 ;

$y_{1}-$ parameter characterizing the intensity of forgetting by spreaders covered by the source 1 ;

$\gamma_{2}-$ parameter characterizing the intensity of forgetting by spreaders covered by the source 2 ;

$\delta_{1}$ - parameter characterizing the intensity of forgetting by pre-spreaders covered by the source 1 ;

$\delta_{2}$ - parameter characterizing the intensity of forgetting by pre-spreaders covered by the source 2 ;

$\mathrm{N}_{1}$ - the number of the first group;

$\mathrm{N}_{2}$ - the number of the second group.

Investigation of this model were conducted with the use of numerical methods. Special attention was given to the case when one information source has a stronger propaganda through the media, and the second one has a "viral" information, i.e. $\alpha_{1}>\alpha_{2}, \beta_{2}>\beta_{1}$.

The results of numerical experiments show that the dynamics for each of the groups is as follows: at first the number of pre-spreaders increases and reaches its maximum, then it decreases, while the number of spreader increases. Fig. 4 and Fig. 5 show the dynamics of the number of spreaders and pre-spreaders from both groups in the experiment with the following parameters:

$N_{1}=100, N_{2}=200, \gamma_{1}=0,01, \gamma_{2}=0,3, \delta_{1}=0,1, \delta_{2}=0,02, \alpha_{1}=0,13, \alpha 2=0,06, \beta_{1}=0,04, \beta_{2}=0,1$. 

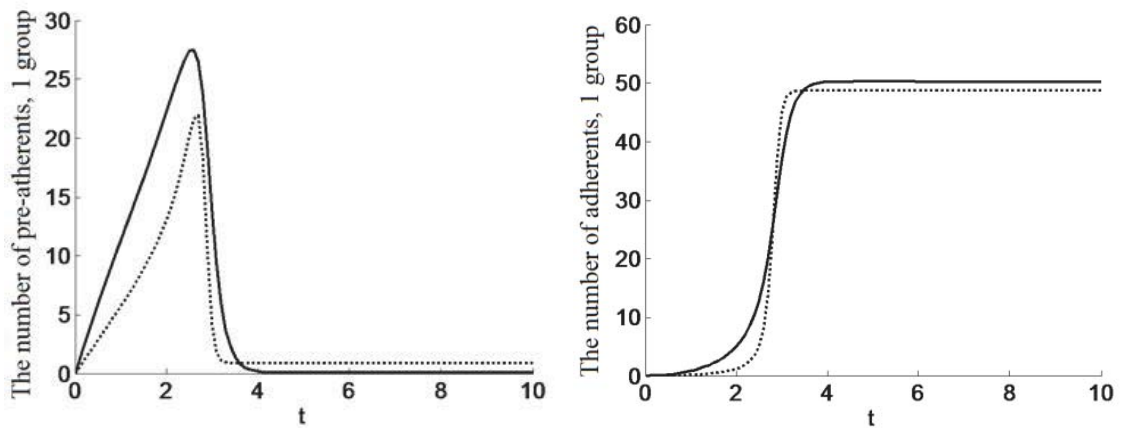

Figure 4. The dynamics of the number of spreaders and pre-spreaders from the first group.

Full lines are $x(t)$ and $X(t)$ respectively, dotted lines are $y(t)$ and $Y(t)$ respectively.
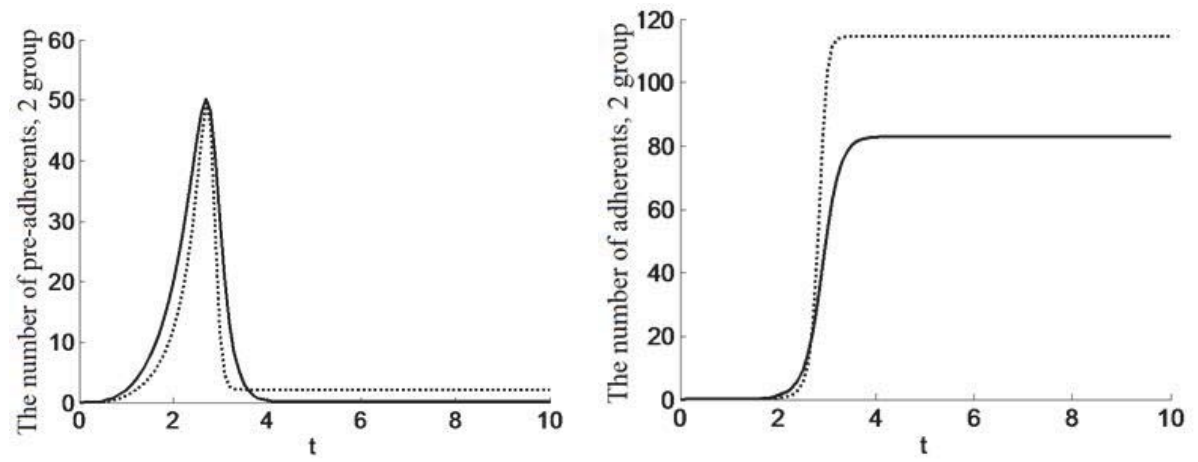

Figure 5. The dynamics of the number of spreaders and pre-spreaders from the first group.

Full lines are $x(t)$ and $X(t)$ respectively, dotted lines are $y(t)$ and $Y(t)$ respectively

Fig. 4 and 5 show that the majority of members of the first group (i.e. individuals who use the media) are covered by the first source (i.e. $X_{1}(t)>Y_{1}(t)$ for large $t$ ), and the majority of the members of the second group (i.e. individuals who don't use the media) are covered by the second source (i.e. $X_{2}(t)<Y_{2}(t)$ for large $\left.t\right)$. But for the first group the "superiority" of first source is insignificant, while in the second group the difference between those who are covered by the first source, and those who believe the second one, is much large. This is due to the fact that "viral" second information source strongly affects both groups (since individuals from different groups communicate with each other), while the first source prevails only in the first group.

If we increase coefficients $\alpha_{1}$ and $\beta_{2}$ are large then the second group becomes completely captures by there is a complete "capture" of the second group by the second source and a stronger predominance of people covered by the first source in the first group. Thus, increase of information forgetting leads to a shift of the final distribution in favor of the second source. The reason for this is that the "forgetful" individuals are more recruited by the second source than by the first one.

\section{Conclusion}

In this article we consider a set of models of information attack and information warfare in a society, taking into account both information dissemination in the interpersonal communication and propaganda through the media. The process of confrontation is that two sources spread information in a society so that each individual can become a spreader of either one or the other (depending on the kind of information she received first); also there are two opposing media in the 
system and the information of both sources can be spread through rumors. An spreader disseminates information of her "party", and she is impervious to the opposite information course. The winner of the confrontation is the source which has a larger number of spreaders to a particular point $t$ (for example, to $t$ tending to infinity).

The methods of mathematical formalization of such factors of the spread of information as information forgetting by individuals, non-coverage of a society by the media and the two-step adoption and forgetting of the information by individuals are developed.

We created Mathematical model of information warfare in a society by adding three factors listed above to the basic model. Our model has the form of the Cauchy problem for nonlinear system of eight ordinary differential equations. The series of numerical experiments was carried out, the meager attention was paid to the case when one source has more intensive media propaganda, but the information from the other source more rapidly spreads through interpersonal communication (i.e. in the system there are two large parameters of the same order). It was found that in the part of the society that receives information both through the media and interpersonal communication, a steady ratio between the number of spreaders of both sides establishes over time, and these numbers have the same order (with above parameters proportional tend to infinity). At the same time, in the part of the society that receives the information only through interpersonal communication, the number of spreders в стационарном состоянии was established the stationary level at which the number of spreaders of the second source are much greater then numbers of spreaders of the first source.

\section{References}

Daley D.J., Kendall D.G. (1964). Stochastic Rumors // Journal of the Institute of Mathematics and its Applications. Vol. 1, pp. 42-55.

Duffy D., Rowden L. (2005). You are what you read. MORI research Institute.

Gubanov D.A., Novikov D.A., Chkhartishvili A.G. (2010). Sotsialnye seti: modeli informatsionnogo vliianiia, upravleniia i proitivoborstva (Social Nets: Models of Information Influence, Control and Warfare). - Fizmatlit, $228 \mathrm{~s}$.

Janagizawa-Drott D. (2014). Prapaganda and Conflict: Evidence from the Rwandan Genocide. . The Quarterly Journal of Economics.

Marevtseva N. A., Valliulin A.N. (2014). Vychislitelnye eksperimenty s modeliami informatsionnogo protivoborstva (Computational Experiments with Models of Information Warfare) // Matematicheskoe modelirovanie sotsialnykh protsessov. Vypusk 14. M.: Maks-press. S. 62-80.

McGuire, W.G. (1985). Attitudes and attitude change. In G. Lindzey\&E. Aronson (Eds.), Hand-book of social psychology (3rd ed., Vol 2, pp. 233-346). New York: Random House.

Mikhailov A. P., Marevtseva N. A. Models of information warfare // Mathematical Models and Computer Simulations. Volume 4, Issue 3, pp 251-259.

Mikhailov A. P., Petrov A. P., Marevtseva N. A.,. Tretiakova I. V. (2014). Development of a Model of Information Dissemination in Society // Mathematical Models and Computer Simulations, Vol. 6, No. 5, pp. 535-541, 2014.

Mikhailov A.P., Izmodenova K.V. (2005). Ob optimalnom upravlenii protsessom rasprostraneniia informatsii (On optimal Control of Information Dissemination Process) // Matematicheskoe modelirovanie, 17, №5, s.67-76.

Mikhailov A.P., Izmodenova K.V. (2014). Ob optimalnom upravlenii v matematicheskoi modeli rasprostraneniya informatsii (On optimal Control in Matematical Model of Information Dissemination) // Trudy seminara «Matematichestoe modelirovanie sotsialnykh protsessov», Sbornik, vyp. 6. M.: Maks-press.

Mikhailov A.P., Kliusov N.V. (2002). O svoistvakh prosteishei matematicheskoi modeli rasprostraneniia informatsionnoi ugrozy (On properties of Basic Model of Information Menace Dissemination) // Matematicheskoe modelirovanie sotsialnyh protsessov. Vyp.4. - M. MAKS Press, s.115-123.

Petrov A.P., Maslov A.I., Tsaplin N.A. (2015). Modeling of making choices by individuals during information warfare in society /I Mathematical Models and Computer Simulations.

Samarskii A.A,. Mikhailov A.P. (2001). Principles of Mathematical Modelling: Ideas, Methods, Examples. CRC Press, 360 p.

Samarskii A.A., Mikhailov A.P. (2004). Matematicheskoe modelirovanie $v$ informatsionnyiu epokhu (Mathematical Modelling in Information Age). Vestnik RAN, N. 9.

Samarskii A.A., Mikhailov A.P. (2000). Metodologicheskie osnovy modelirovaniia sotsialnykh protsessov: predely vozmozhnogogo (Metological Base for Modelling of Social Processes: the Boundaries of Possibilities) I/. Matematicheskoe modelirovanie sotsialnykh protsessov. vyp.3. M.: MGU.

Shvedovskii V.A. (1981). Modelirovanie rasprostraneniya informatsii v smezhnykh sotsialnykh gruppah (Modelling of Information Dissemination in Adjacent Social Groups) // Metamaticheskie metody v sotsiologicheskom issledovanii. Nauka, s.207-214.

Thompson K., Castro Estrada R., Daugherty D., Cintron-Arias A. (2003). A Deterministic Approach to the Spread of Rumors // Working paper, Washington, DC, USA.

Vasilieva A., Butuzov V., Kalachev L. (1995). The boundary function method for singular perturbation problems, SIAM, Philadelphia. 